\section{AMC}

Vol. 57 No. 4 2015

\title{
En este número
}

\author{
Efectos agudos del ejercicio en la presión arterial. Implicaciones terapéuticas en pacientes \\ hipertensos (Álvarez-Aguilar) Pág 163
}

Menciona el autor de este artículo de revisión que "el tratamiento con ejercicio de la hipertensión arterial es una herramienta terapéutica que puede contribuir al control de las cifras tensionales de los pacientes hipertensos, reducir su necesidad de medicamentos, mejorar su calidad de vida, disminuir la mortalidad cardiovascular y otras comorbilidades. El dominio de los fundamentos de prescripción de ejercicio en pacientes hipertensos es una herramienta con un alto potencial terapéutico que debería ser manejada por cualquier médico general. En este trabajo se abordan los mecanismos fisiológicos implicados en la hipotensión post-ejercicio y las bases de la prescripción de un plan de ejercicio en pacientes hipertensos."

\section{Efectos del riluzol en la evolución clínica y sobrevida de los pacientes con esclerosis lateral amiotrófica en Costa Rica (Abadía-Cubillo et al.) Pág 172}

El objetivo de este artículo original fue "evaluar el impacto del riluzol en la evolución clínica y sobrevida de los pacientes con esclerosis lateral amiotrófica atendidos en el Centro Nacional de Control del Dolor y Cuidados Paliativos. Es un estudio analítico, observacional y retrospectivo basado en los registros de los pacientes, que analizó 235 expedientes clínicos, de los cuales 142 (60\%) estaban en tratamiento con riluzol". Luego del análisis de los resultados, concluyen los autores que "en los pacientes que utilizaban riluzol se demostró un incremento en la sobrevida de 7 meses comparado con los que no lo utilizaron $(\mathrm{p}=0,17)$ y evidenció que los pacientes que tomaron el medicamento mostraron un retraso en la colocación de la gastrostomía endoscópica percutánea".

\section{Actitudes y conocimientos sobre la donación de órganos, trasplante y muerte cerebral en estudiantes de ciencias de la salud (Padilla-Cuadra et al.) Pág 179}

En este estudio los autores se propusieron "determinar la actitud y nivel de conocimiento sobre la donación de órganos, trasplante de órganos y muerte cerebral en estudiantes de ciencias de la salud". Para ello encuestaron a "estudiantes de ciencias de la salud, de las carreras de Medicina, Enfermería, Psicología y Farmacia de la Universidad de Iberoamérica". Encuestaron a 326 estudiantes, 73\% de mujeres, con una edad media de 23,25 años. Dentro de los resultados obtenidos describen que "un $90,8 \%$ mostró disposición a donar sus órganos, pero solo el 35,3\% contaba con documentación que lo identificara como donante. Un $26,3 \%$ tiene el concepto equivocado de que la muerte cerebral es una condición reversible y un $44,8 \%$ de los encuestados no distingue entre muerte cerebral y estado neurovegetativo persistente".

Hipocalcemia e hipoparatiroidismo post-tiroidectomía (Barquero-Melchor et al.) Pág 184

Mencionan los autores de este estudio que "la hipocalcemia y el hipoparatiroidismo son complicaciones frecuentes tras la tiroidectomía. Sin embargo, su incidencia varía ampliamente en la literatura médica y sus factores de riesgo no están bien establecidos". Además señalan que no existen datos sobre estas complicaciones a nivel nacional. Realizaron un estudio prospectivo en el que incluyeron 35 casos, encontrando que "catorce $(42,4 \%)$ de los treinta y cinco pacientes sometidos a tiroidectomía desarrollaron hipocalcemia, y ocho $(22,8 \%)$ sufrieron hipoparatiroidismo. En el procedimiento quirúrgico de tiroidectomía total, se presentó una mayor incidencia de hipocalcemia (50\%) y de hipoparatiroidismo $(28,6 \%)$ cuando se comparó con el procedimiento de tiroidectomía subtotal." Concluyen los autores que "la hipocalcemia y el hipoparatiroidismo son complicaciones frecuentes de la tiroidectomía, particularmente tiroidectomía total por cáncer o con linfadenectomía cervical”.

Tumores del timo. Estudio retrospectivo de 38 casos operados en el Hospital "Dr. Rafael Ángel Calderón Guardia” entre 1996 y 2013 (Mainieri-Hidalgo y Mainieri-Breedy) Pág 190

El objetivo de este trabajo origina fue "valorar los resultados obtenidos con 38 pacientes intervenidos por tumores del timo" que correspondían a "todos los pacientes intervenidos por tumores del timo durante el período de 1996 a 2013 en el Hospital "Dr. Rafael Ángel Calderón Guardia". Reportan los autores en los resultados que "se intervinieron 38 pacientes por tumores del timo en los 17 años evaluados, 20 hombres y 18 mujeres con promedio edad de 50 años. En 26 casos se realizó resección, la cual en 19 fue macroscópicamente completa. Se reportaron 20 tumores malignos y 18 benignos." Entre las conclusiones comentan los autores que "el método de detección más útil fue la radiografía de tórax y la vía más utilizada para tomar biopsia fue mediastinotomía”. 


\section{De Tutankamón de Tebas a la genómica y biología molecular}

A través de la Academia Nacional de Medicina, en el Colegio de Médicos y Cirujanos de nuestro país, ofrecimos una charla sobre este tema, que se puede consultar vía Internet. ${ }^{1}$

Uno de los hechos históricos más sobresalientes de la Egiptología ha sido el descubrimiento de la tumba de Tutankamón, casi intacta, por Howard Carter (1922), luego de años de investigar en la Necrópolis del Valle de los Reyes, en Tebas (Luxor), en la margen oriental del río Nilo.

El mecenas de Carter fue Lord Earl de Carnavon, por años. El descubrimiento de la entrada a la tumba de Tutankamón, accidentalmente fue realizado por Hussein Abdel Rasoul, un niño de 10 años que llevaba agua a los obreros de Carter y se tropezó con la entrada a las gradas que iban a la tumba, y se encontraban cubiertas por arena.

Carter conocía muy bien el esperado hallazgo y por telegrama informó a Lord Carnavon, en Inglaterra, quien viajó por buque a Alejandría, Egipto, acompañado por su hija. En su presencia, al abrir la Cámara de los Tesoros, preguntó su mecenas: “Qué cosas ves?”, y respondió Carter: "Veo cosas maravillosas.”. Ese fue sin duda el mayor descubrimiento arqueológico del siglo XX.

Tutankamón, joven faraón, undécimo de la dinastía XVIII, del periodo Nuevo Reino, falleció hace 3360 años, a los 18 años, probablemente a causa de malaria y enfermedades óseas, heredadas por la consanguinidad real existente. No ha sido de los faraones más relevantes, por su corta edad; se cree que su funeral y momificación fueron precipitados, en una tumba que no había sido construida para él, sino que resultó improvisada. Debe recordarse que en esta cultura había un culto al más allá, y el faraón pasaba toda su vida planeando y edificando su última morada.

Quizás lo más extraordinario fue encontrar la tumba casi íntegra, pues a pesar de haber sido violada en dos ocasiones en el transcurso del tiempo, afortunadamente se conservó la mayoría de los tesoros.

Tutankamón fue hijo de Akenathon, quien quiso establecer el monoteísmo, lo que crearía una inestabilidad que fue resuelta en tiempos de Tutankamón, al regresar al politeísmo.

Hoy, con estudios de paleoantropología, estratigrafía, medicina forense, tomografía axial, resonancia magnética, radionucleidos de carbono y uranio, ADN, cromatografía, biología molecular y otros, se conoce la cronología y la genealogía de la familia del joven faraón, tanto como las causas de muerte, con gran precisión. ${ }^{2}$

Los científicos han extraído con sumo cuidado, fragmentos de las momias a los cuales se les ha analizado el $\mathrm{ADN}^{2}$

La riqueza encontrada en las cámaras adyacentes revela una época afortunada para Egipto. Cuando Napoleón estuvo en 1798 en la Batalla de la Pirámides en Giza, El Cairo, dijo a sus soldados: "Cincuenta siglos de historia os contemplan".

Nacería entonces la Egiptología con personas como Jean Francois Champolion, fallecido en 1832, quien descubrió mediante la Piedra Rosetta (hoy en el Museo Británico), la transcripción de la escritura jeroglíica real, pues existen tres tipos diferentes de esa escritura.

Lastimosamente, muchos investigadores tenían propósitos no científicos, por lo que importantes eslabones se perdieron, fueron robados o destruidos, o lo que es aun más grave, fueron mal manipulados por ignorancia, sin observar los principios de la arqueología. En ocasiones se carecía de estudios idóneos, y muchas de las técnicas de excavación fueron inadecuadas. 
Lo fundamental del descubrimiento es la preservación de la mayoría de las valiosas piezas, unas 6000 encontradas, aunque lamentablemente, en el Museo en El Cairo, que visitamos 23 y 5 años atrás, predominan condiciones de deterioro, y lo que es más grave, a raíz del daño provocado por los graves vaivenes políticos y militares que afectan Egipto desde hace varios años, se conoce que algunos objetos han desaparecido o se han deteriorado para siempre. ${ }^{3-4}$

Hace poco, la máscara mortuoria de Tutankamón se cayó mientras era limpiada en el Museo de El Cairo, y así se fracturó la barba, cuya reconstrucción se realizó con una tecnología inadecuada.

Notable ha sido la labor del exministro de Estado de Antigüedades, Dr. Zahi Hawass, en su lucha por recuperar valiosas reliquias, como el busto de Nefertiti (en el Neues Musseum de Berlín), la Piedra Rosetta (en el Museo Británico de Londres), y los múltiples obeliscos, entre otras piezas arqueológicas, compradas o saqueadas, por doquier.

El Dr. Hawass se ha destacado también por múltiples descubrimientos arqueológicos, como el de la momia de la faraona Hatshepsut, fallecida hace 3575 años, y quien fuera una destacadísima reina, que influyó en el poderío imperial; hoy su templo mortuorio está en el Valle de las Reinas, en Luxor.

Otras mujeres también destacadas como faraonas, fueron: Tawosret, fallecida hace 3215 años y Cleopatra, de hace 2345 años (periodo Grecorromano, en la decadencia del Imperio Egipcio).
Hawass ha recibido el epíteto del "Indiana Jones" moderno, y actualmente, gracias a la inestabilidad política, radica en los Estados Unidos, donde dicta conferencias en museos y universidades.

Cada día se van revelando nuevos hallazgos, y se calcula que hay unas 22 tumbas reales sin descubrir. El mito de la venganza del faraón se convertiría en una leyenda romántica, vulgarizada principalmente por el cine.

Desafortunadamente, la mayoría de las tumbas reales fueron, en múltiples ocasiones, violadas y saqueadas, debido a las riquezas contenidas, que ahora son piezas perdidas para siempre.

En resumen, la importancia de las investigaciones científicas consiste en dilucidar el arte y la cultura del Egipto Milenario, y la preservación y recuperación de obras dispersas por el mundo, así como el conocimiento de la genealogía de los personajes principales, la consanguinidad, la causa de muerte y las enfermedades existentes. Esto se ha logrado adecuadamente con refinadas técnicas de análisis del ADN, y así se han preservado múltiples papiros que revelan historia, secretos, costumbres y mitos de la cultura egipcia, entre ellos el de Edwin Smith, el de Ebers, y el de Kahun, acerca de temas ginecológicos.

El Libro de los muertos, por ejemplo, contempla el conocimiento necesario para preparar el viaje al más allá, y hay también otros papiros referentes a la Medicina de esas épocas.

Es de esperar que los cambios económicos, políticos y militares no sigan deteniendo descubrimientos, o destruyendo y comerciando con los fragmentos de la historia. Sin embargo, es claro que muchas

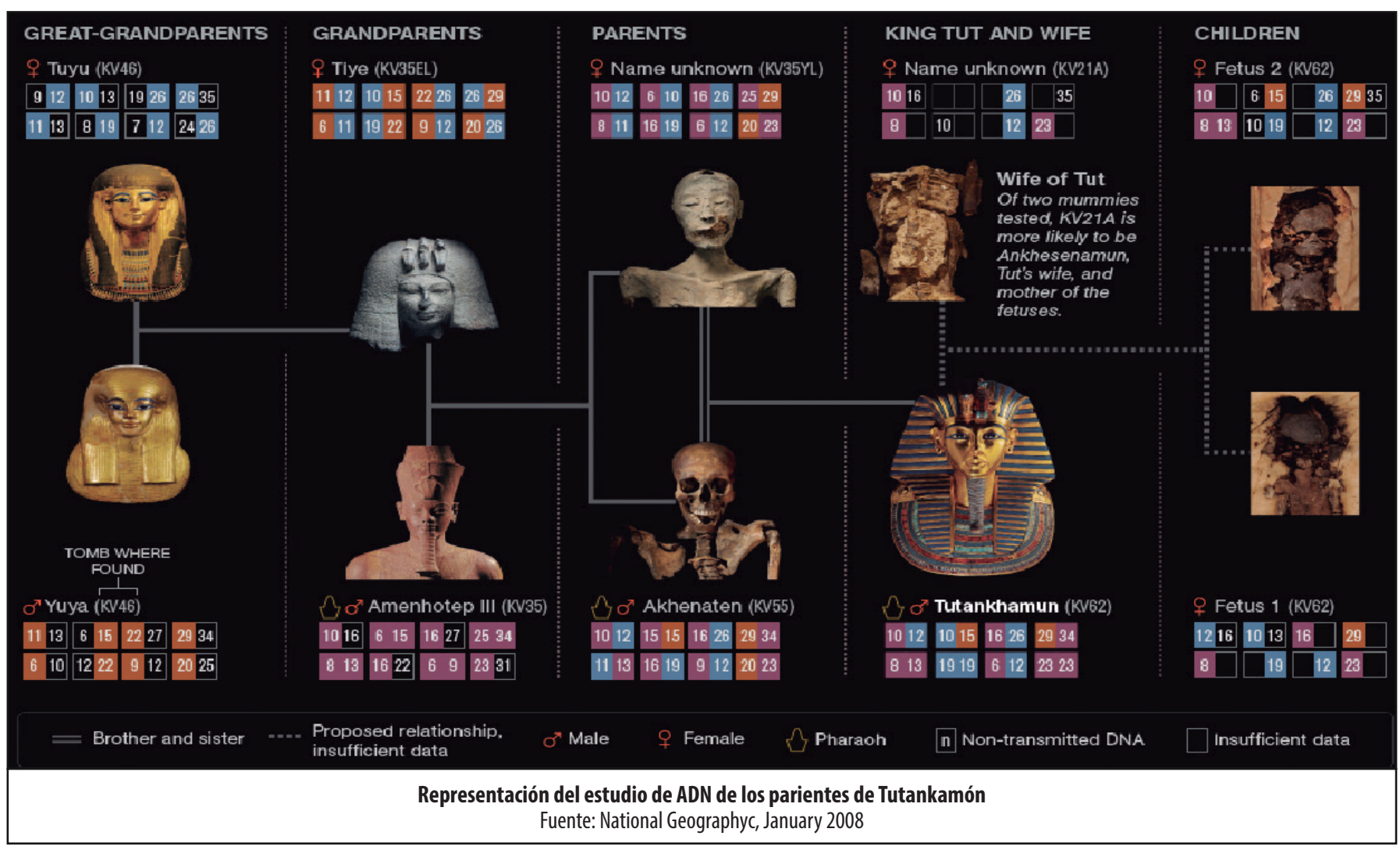


de las piezas en el extranjero, no regresarán jamás, a pesar de lo cual se debe promover su conservación y respeto. Por fortuna, muchos investigadores y especialistas internacionales y egipcios continúan con los estudios, por lo que la Egiptología se reconoce como gestora de investigaciones académicas acreditadas.

Como bien lo decía el distinguido cirujano vienés, Theodor Billroth, fallecido en 1894, "Solamente los hombres que conocen el arte y ciencia del pasado, son competentes para ayudarnos en su progreso, para el futuro".

Dr. Teodoro Evans Benavides
Académico de Número
Academia Nacional de Medicina
tevans@racsa.co.cr

\section{Referencias}

1. https://www.youtube.com/watch?v=cWpxICZ5pBO (feb 2015).

2. Hawass $Z$, et al. Ancestry and Pathology in King Tutankamun Family. JAMA. 2010; 303:638-647.

3. National Geographic, Set. 2010 (págs 34-59).

4. PIAM, UCR. Curso Historia del Arte, 2013-2014-2015.

Fe de erratas:

1. Se aclara que el artículo titulado: Síndrome de Wilkie, publicado en la revista Vol 57, No. 3, 2015 páginas 145-148, el orden correcto de los autores es el siguiente: Francisco Poblete-Otero, Humberto Álvarez-Pertuz, Andrés Arana-Sáenz y Natalia María Grant-Vega. Por error en la publicación inicial se omitió el nombre de la autora Natalia María Grant-Vega. 